
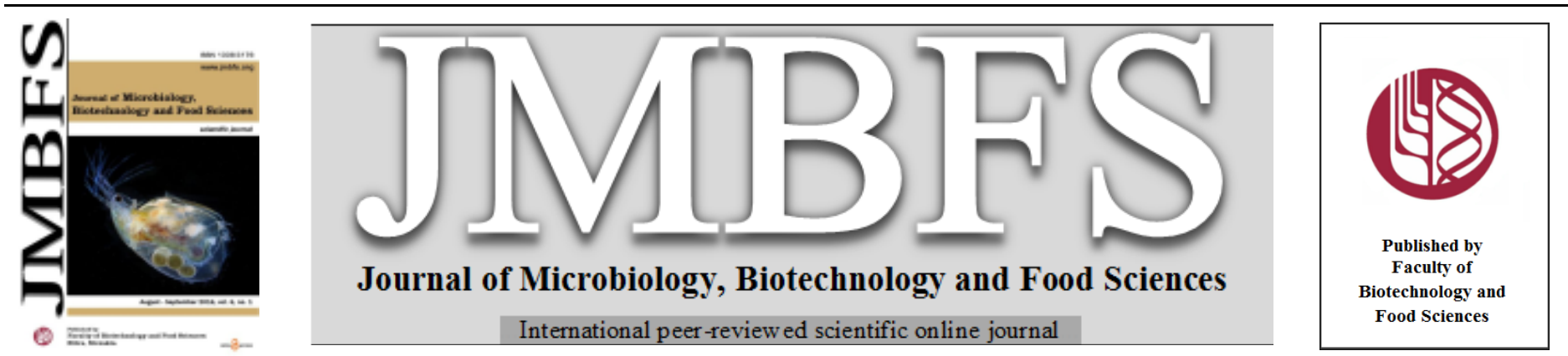

\title{
OPTIMAZTION OF GAMMA-DECALACTONE PRODUCTION BY YEAST YARROWIA LIPOLYTICA USING THE TAGUCHI METHOD
}

\author{
Hamideh Moradi $^{1}$, Mohammad Ali Asadollahi ${ }^{1, *}$, Iraj Nahvi $^{2}$ \\ Address(es): Dr. Mohammad Ali Asadollahi (Ph.D.) \\ ${ }^{1}$ Department of Biotechnology, Faculty of Advanced Sciences and Technologies, University of Isfahan, Hezar Jarib street, Isfahan 81746-73441,Iran, +98-31- \\ 37934263. \\ ${ }^{2}$ Department of Biology, Faculty of Sciences, University of Isfahan, Hezar Jarib street, Isfahan 81746-73441,Iran.
}

*Corresponding author: ma.asadollahi@ ast.ui.ac.ir

doi: 10.15414/jmbfs.2016.6.1.685-688

\section{ARTICLE INFO}

Received 17. 10. 2014

Revised 13. 3. 2016

Accepted 5. 4. 2016

Published 1. 8. 2016

Regular article

OPEN $\partial_{\text {ACCESS }}$

\section{ABSTRACT}

The $\gamma$-decalactone is one of the lactones with peachy aroma which has been approved as food additive by FDA. The aim of this study was to optimize media composition and conditions for microbial biotransformation of ricinoleic acid and castor oil as substrates to $\gamma$ decalactone using the yeast Yarrowia lipolytica. The Y. lipolytica DSM 3286 strain was used as biotransformation agent in different trails designed by Taguchi method. The highest concentration of $\gamma$-decalactone was 62.4 and $52.9 \mathrm{mg} / \mathrm{L}$ from $1.5 \%$ ricinoleic acid and $2.5 \%$ castor oil, respectively. Nitrogen sources exhibited significant effect on the biotransformation. The maximum $\gamma$-decalactone production occurred at $\mathrm{pH}$ 6. The results showed that the composition of biotransformation medium composition is important for $\gamma$ decalactone production.

Keywords: $\gamma$-Decalactone, Yarrowia lipolytica, Ricinoleic acid, Castor oil, Biotransformation, Taguchi method

\section{INTRODUCTION}

Lactones are attractive molecules as additive for food and pharmaceutical products due to their pleasant flavor. The $\gamma$-decalactone is one of the lactones with peach flavor which has been approved as food additive by FDA. Microbial production of flavors as an alternative route to extraction from plants or chemical synthesis has received great deal of attention. A variety of microorganisms can be used to synthesize flavor compounds using simple nutrients. The main driving force for microbial production of flavor compounds is that the flavor compounds produced by microorganisms can be labeled as "natural" (Longo \& Sanromán, 2006; Scharder, 2007; Schrader, Etschmann, Sell, Hilmer, \& Rabenhorst, 2004). Lactones are ubiquitous flavor and aroma constituents of many essential oils and plant volatiles (Başer \& Demirci, 2007). The $\gamma$-decalactone, the lactone of 4-hydroxydecanoic acid, is the most widely used flavor lactone exhibiting an oily-peachy aroma. Okui et al. were the first who noticed the accumulation of $\gamma$ decalactone during the growth of a Candida species on ricinoleic acid (Okui, Uchiyama, \& Mizugaki, 1963; Romero-Guido et al., 2011).

The medium composition is of great importance in microbial production of $\gamma$ decalactone. Microorganisms can use ricinoleic acid as suitable substrate for production of this aroma compound (Lee \& Chou, 1994). Castor oil which contains $85 \%$ of ricinoleic acid could be used as readily available, inexpensive substrate for $\gamma$-decalactone production (Dufosse et al., 1998; Neto, Pastore, \& Macedo, 2004).

Environmental conditions such as temperature and $\mathrm{pH}$ are important and influence the $\gamma$-decalactone production. The nitrogen sources effect on this fermentation is complex. The highest yields were obtained using complex nitrogen sources which is probably due to supplying trace nutrients and minimizing the toxic effects of fatty acids by sequestering them (Maume $\&$ Cheetham, 1991).

The non-conventional yeast Yarrowia lipolytica have good potential to production of $\gamma$-decalactone. In the previous studies, this yeast has been used for $\gamma$-decalactone production from ricinoleic acid and castor oil as substrates (Aguedo, Wache, Belin, \& Teixeira, 2005; N. Gomes, Teixeira, \& Belo, 2010; Moradi, Asadollahi, \& Nahvi, 2013).

Since control of bioconversion parameters was shown to significantly affect $\gamma$ decalactone production, a large number of experiments are needed to optimize bioconversion conditions (Lee \& Chou, 1994). To circumvent this problem, Taguchi method was used for optimization of bioconversion conditions. Taguchi method requires only a small number of experiments to study the entire parameters involved in process. Furthermore, this method allows studying effects of multiple factors on the process yield in a fast and economic way using an orthogonal array design (Montgomery, 1991). Taguchi method shows the importance of distinct values to improve the process and product quality (Fraley, Oom, Terrien, \& Alewsk, 2007). This study therefore aimed to optimize important factors affecting $\gamma$-decalactone production from ricinoleic acid and castor oil as substrates by the Taguchi method.

\section{MATERIAL AND METHODS}

\section{Microorganism and culture conditions}

Y. lipolytica DSM 3286 was cultured on YPD medium at $29{ }^{\circ} \mathrm{C}$, and maintained at $4{ }^{\circ} \mathrm{C}$ on YPD-agar (Barth \& Gaillardin, 1996). Basal main medium for $\gamma$ decalactone contained ricinoleic acid or castor oil, yeast extract, peptone. The flasks were incubated in shaker-incubator at $200 \mathrm{rpm}$ and $29{ }^{\circ} \mathrm{C}$ (Moradi $\boldsymbol{e t}$ al., 2013).

\section{Design of experiments}

The Taguchi fractional factorial experiment design approach has been used for optimization of production variables. It is a robust methodology agains uncontrollable environmental changes (Patil, Sachin, Wakte, \& Shinde, 2014). The Qualitek-4 software was used for Taguchi experimental design in this research. In the previous study, it was shown that substrate (ricinoleic acid or castor oil), yeast extract concentration, peptone concentration, and $\mathrm{pH}$ are the four main factors affecting production of $\gamma$-decalactone by $Y$. lipolytica (Moradi et al., 2013). Therefore, these four main factors were used each at four levels as shown in Tables 1-3.

\section{Lactone extraction and detection}

For extraction and analysis of $\gamma$-decalactone, $50 \mathrm{mg} / \mathrm{L}$ of $\gamma$-valerolactone (internal standard) was added to $2 \mathrm{~mL}$ of filtered sample of the culture medium (Alchihab et al., 2009). Afterwards, diethyl ether was used as organic phase to lactone extraction (Aguedo, Wache, Coste, Husson, \& Belin, 2004; Groguenin et al., 2004). The ether layer was recovered and the analysis was performed with HP6890 gas chromatograph (Agilent) equipped to an FID detector. The analytes were separated on a HP-5 capillary column with helium as carrier gas at a flow 
rate of $3 \mathrm{~mL} / \mathrm{min}$. A split/splitless injector was used in the split mode (split ratio 1:30). The injector and FID temperatures were 200 and $250{ }^{\circ} \mathrm{C}$, respectively. The oven temperature was increased from 60 to $195{ }^{\circ} \mathrm{C}$ at a rate of $20{ }^{\circ} \mathrm{C} / \mathrm{min}$ and then at a rate of $10{ }^{\circ} \mathrm{C} / \mathrm{min}$ to $270{ }^{\circ} \mathrm{C}$ (An, Joo, \& Oh, 2013; Moradi et al., 2013).

\section{RESULTS}

In order to investigate the best conditions for optimum $\gamma$-decalactone production from ricinoleic acid or castor oil as substrates by $Y$. lipolytica DSM 3286, trails were done according to experiments proposed by the Qualitek-4 software (Fig. 1 and Fig. 2).

In the case of ricinoleic acid as substrate, maximum $\gamma$-decalactone production of $62.4 \mathrm{mg} / \mathrm{L}$ was obtained at concentrations of ricinoleic acid $15 \mathrm{~mL} / \mathrm{L}$, peptone 3 $\mathrm{g} / \mathrm{L}$, and yeast extract $9 \mathrm{~g} / \mathrm{L}$ at $\mathrm{pH} 6$ (Trail 10).

The main effects of each factor on $\gamma$-decalactone production from ricinoleic acid by $Y$. lipolytica DSM 3286 were determined by Qualitek-4 software (Fig. 3). Lower $\gamma$-decalactone production rate was observed at higher ricinoleic acid concentrations and $\mathrm{pH}$ whereas increasing yeast extract concentration had positive effect and enhanced production rate of $\gamma$-decalactone. Peptone concentration had variable effects on $\gamma$-decalactone production.

Optimum conditions for $\gamma$-decalactone production from castor oil were obtained as $25 \mathrm{~mL} / \mathrm{L}$ of castor oil, $9 \mathrm{~g} / \mathrm{L}$ of peptone and yeast extract, and $\mathrm{pH} 6$ in which $52.9 \mathrm{mg} / \mathrm{L}$ of $\gamma$-decalactone was produced. However, this combination had not been used in any of the experiments designed by the software.

The main effects of each factor on $\gamma$-decalactone production from castor oil by $Y$. lipolytica DSM 3286 were determined by Qualitek-4 software (Fig. 4). If increase the amounts of castor oil and yeast extract, the production of $\gamma$ decalactone will be increased. Peptone had no significant effect on $\gamma$-decalactone production. Acidic $\mathrm{pH}$ is better than neutral $\mathrm{pH}$ for production of $\gamma$-decalactone by $Y$. lipolytica DSM 3286 (Fig. 4).

Since maximum $\gamma$-decalactone titer was observed at the highest concentration of castor oil $(25 \mathrm{~mL} / \mathrm{L})$, the effect of higher concentrations of castor oil on the $\gamma$ decalactone production was examined. However, it was found that higher concentrations of castor oil did not further improve $\gamma$-decalactone production (Fig. 5).

Table 1 Levels of factors for ricinoleic acid as substrate

\begin{tabular}{lcccc}
\hline Factors & Level 1 & Level 2 & Level 3 & Level 4 \\
\hline Ricinoleic acid (mL/L) & 5 & 10 & 15 & 20 \\
Peptone (g/L) & 0 & 3 & 6 & 9 \\
Yeast extract (g/L) & 0 & 3 & 6 & 9 \\
$\mathrm{pH}$ & 4 & 5 & 6 & 7 \\
\hline
\end{tabular}

Table 2 Levels of factors for castor oil as substrate

\begin{tabular}{lcccc}
\hline Factors & Level 1 & Level 2 & Level 3 & Level 4 \\
\hline Castor oil $(\mathrm{mL} / \mathrm{L})$ & 10 & 15 & 20 & 25 \\
Peptone $(\mathrm{g} / \mathrm{L})$ & 0 & 3 & 6 & 9 \\
Yeast extract $(\mathrm{g} / \mathrm{L})$ & 0 & 3 & 6 & 9 \\
$\mathrm{pH}$ & 4 & 5 & 6 & 7 \\
\hline
\end{tabular}

Table 3 The L16 orthogonal array for trails

\begin{tabular}{lcccc}
\multicolumn{2}{l}{ Table 3 The L16 orthogonal array for trails } & \\
\hline Trial number & $\begin{array}{c}\text { Ricinoleic } \\
\text { acid or castor } \\
\text { oil }(\mathrm{mL} / \mathrm{L})\end{array}$ & $\begin{array}{c}\text { Peptone } \\
\text { (g/L) }\end{array}$ & $\begin{array}{c}\text { Yeast extract } \\
\text { (g/L) }\end{array}$ & $\mathrm{pH}$ \\
\hline 1 & Level 1 & Level 1 & Level 1 & Level 1 \\
2 & Level 1 & Level 2 & Level 2 & Level 2 \\
3 & Level 1 & Level 3 & Level 3 & Level 3 \\
4 & Level 1 & Level 4 & Level 4 & Level 4 \\
5 & Level 2 & Level 1 & Level 2 & Level 3 \\
6 & Level 2 & Level 2 & Level 1 & Level 4 \\
7 & Level 2 & Level 3 & Level 4 & Level 1 \\
8 & Level 2 & Level 4 & Level 3 & Level 2 \\
9 & Level 3 & Level 1 & Level 3 & Level 4 \\
10 & Level 3 & Level 2 & Level 4 & Level 3 \\
11 & Level 3 & Level 3 & Level 1 & Level 2 \\
12 & Level 3 & Level 4 & Level 2 & Level 1 \\
13 & Level 4 & Level 1 & Level 4 & Level 2 \\
14 & Level 4 & Level 2 & Level 3 & Level 1 \\
15 & Level 4 & Level 3 & Level 2 & Level 4 \\
16 & Level 4 & Level 4 & Level 1 & Level 3 \\
\hline
\end{tabular}

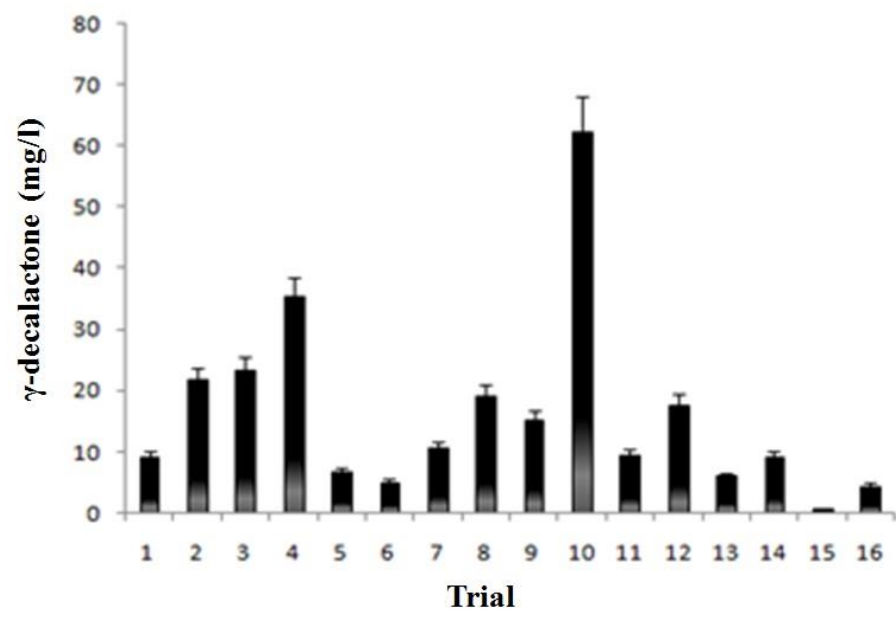

Figure 1 The results of different trails proposed by Qualitek-4 software for $\gamma$ dacalactone production on ricinoleic acid as substrate by $Y$. lipolytica DSM 3286.

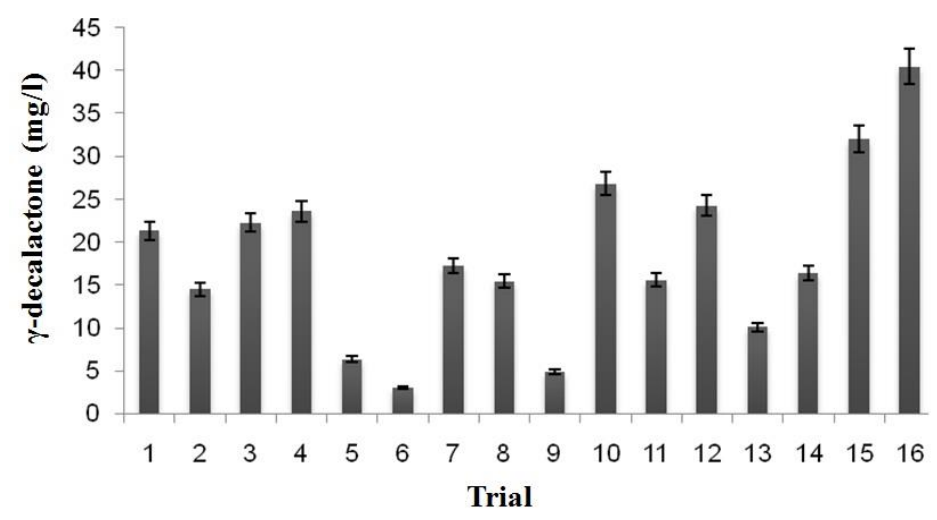

Figure 2 The results of different trails proposed by Qualitek-4 software for $\gamma$ dacalactone production on castor oil as substrate by Y. lipolytica DSM 3286.

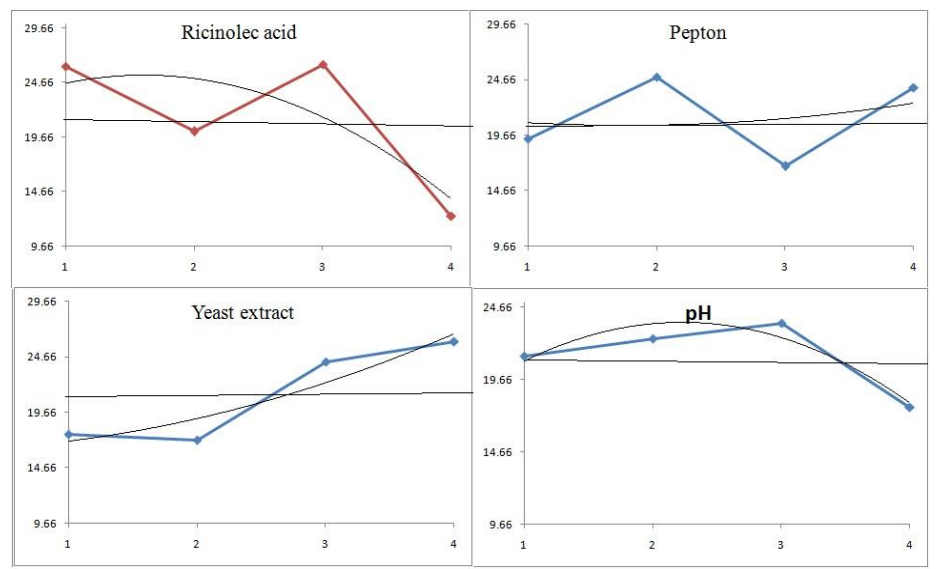

Figure 3 The main effects of each factor on $\gamma$-decalactone production from ricinoleic acid by $Y$. lipolytica DSM 3286 


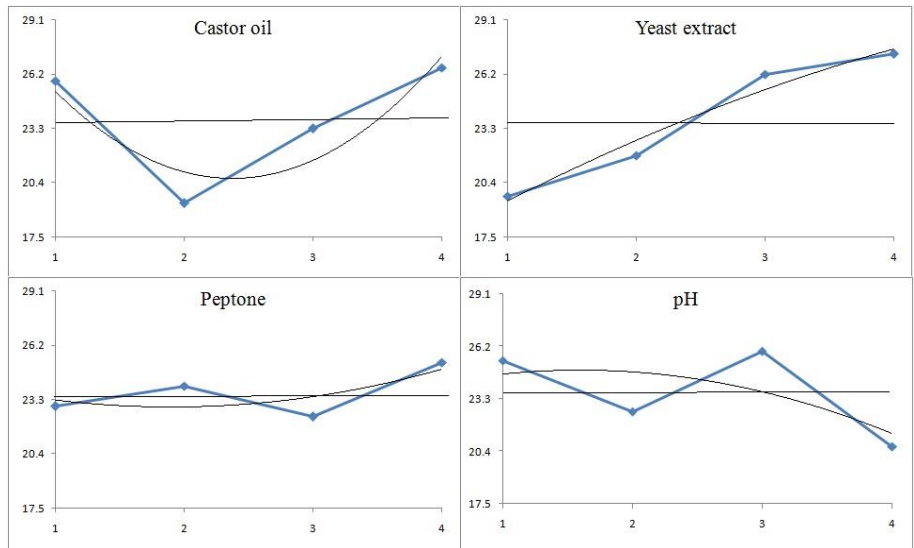

Figure 4 The main effects of each factor on $\gamma$-decalactone production from castor oil by Y. lipolytica DSM 3286.

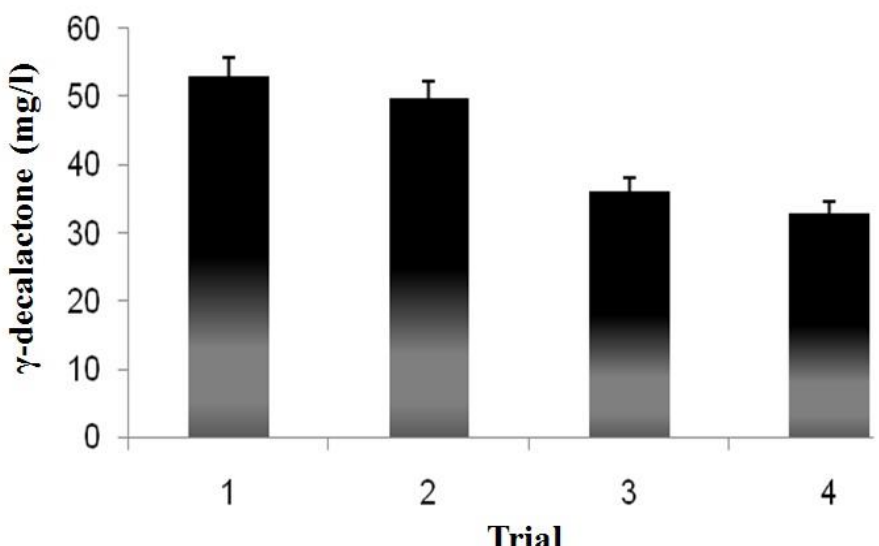

Figure 5 Confirmatory tests for $\gamma$-decalactone production from castor oil by $Y$. lipolytica DSM 3286. Trail (1) is a confirmatory test for proposed experiment by the software; Trails $(2,3,4)$ contain 30,35 and $40 \mathrm{~mL} / \mathrm{L}$ of castor oil, respectively, along with other suggested factors for optimization including peptone $9 \mathrm{~g} / \mathrm{L}$, yeast extract $9 \mathrm{~g} / \mathrm{L}$ and $\mathrm{pH} 6$.

\section{DISCUSSION}

Yeasts are excellent biocatalysts in the field of alkane and fatty acids transformation into dicarboxylic acids and lactones (Waché, 2013). The $\gamma$ decalactone production can be improved by cell density, oil concentration and oxygen transfer rate in batch and step-wise fed-batch cultures of $Y$. lipolytica (Braga \& Belo, 2015).

Some of yeasts such as $Y$. lipolytica can produce $\gamma$-decalactone from ricinoleic acid as key precursor and substrate (Darvishi Harzevili, 2014). Castor oil is natural and nontoxic oil, biodegradable, and a renewable resource obtained from the seeds of the castor plant Ricinus communis (Puthli, Rathod, \& Pandit, 2006). The castor oil is rich in ricinoleic acid and therefore could be used as cheap source for $\gamma$-decalactone production (Braga \& Belo, 2013; Nelma Gomes, Braga, Teixeira, \& Belo, 2013; N. Gomes et al., 2010). Y. lipolytica is able to hydrolyze castor oil to ricinoleic acid and gradually use it, because a high concentration of this acid has inhibitory effect on the growth of yeast cells Presence of castor oil at the beginning of the fermentation and then adding it at a later stage could enhance the $\gamma$-decalactone production level by $Y$. lipolytica because the production of $\gamma$-decalactone needs continuous induction of the $\beta$ oxidation pathways or fatty acid uptake and export systems (Feron, Blin-Perrin, Krasniewski, Mauvais, \& Lherminier, 2005; Maume \& Cheetham, 1991) Yeast extract and peptone were used as nitrogen sources for the production of $\gamma$ decalactone in this research according to previous studies (Alchihab et al., 2009; Moradi et al., 2013).

Four factors with four levels were chosen for optimization of $\gamma$-decalactone production by the Taguchi method as fractional factorial experiment design. First factor was carbon source (ricinoleic acid or castor oil) which have been investigated as substrate and an activator for enzymes in the pathway of $\gamma$ decalactone synthesis in $Y$. lipolytica. Second and third factors were nitrogen sources including yeast extract and peptone that are important to increase cell growth and biotransformation. Last factor was $\mathrm{pH}$ which should be optimized to support maximum cell growth and $\gamma$-decalactone production.

Maximum production of $\gamma$-decalactone was 62.4 and $52.9 \mathrm{mg} / \mathrm{L}$ by $Y$. lipolytica DSM 3286 on ricinoleic acid and castor oil as substrates, respectively. According to the previous studies, the nitrogen source effect was complex on this bioconversion. The $\gamma$-decalactone yield was low in the media with less than $2 \mathrm{~g} / \mathrm{L}$ nitrogen content. Furthermore, a little additional $\gamma$-decalactone was produced in media containing greater than $20 \mathrm{~g} / \mathrm{L}$ of nitrogen concentrations. The function of these complex protein sources is important to increase cell growth and minimize toxic effect in biotransformation (Maume \& Cheetham, 1991; Patil et al., 2014).

The optimum $\mathrm{pH}$ was 6 to $\gamma$-decalactone production for both substrates. The bioconversion of ricinoleic acid into 4-HDA and then $\gamma$-decalactone was obtained at acid $\mathrm{pH}$ (Lee, Lin, \& Chou, 1995). Other researchers used this $\mathrm{pH}$ (Aguedo, Ly, et al., 2004; Alchihab et al., 2009; Wache, Aguedo, LeDall, Nicaud, \& Belin, 2002; Wache, Aguedo, Nicaud, \& Belin, 2003) but in this work pH was optimized step by step from acidic to neutral.

\section{CONCLUSION}

In conclusion, biotransformation medium composition is important for $\gamma$ decalactone production. In particular, interaction of carbon sources and yeas extract as nitrogen source is important. Furthermore, nitrogen sources are important to increase cell growth and biotransformation. Microbial fermentation was used as a potential tool to the production of natural lactones and attractive subject for researchers in this filed. The production of lactone will be established on the industrial scale because it is an extracellular product and can be produced easily with higher yields by culturing yeast in a bioreactor.

\section{REFERENCES}

Aguedo, M., Ly, M. H., Belo, I., Teixeira, J. A., Belin, J. M., \& Wache, Y (2004). The use of enzymes and microorganisms for the production of aroma compounds from lipids. Food Technology and Biotechnology, 42(4), 327-336. Aguedo, M., Wache, Y., Belin, J. M., \& Teixeira, J. A. (2005). Surface properties of Yarrowia lipolytica and their relevance to gamma-decalactone formation from methyl ricinoleate. Biotechnology Letters, 27(6), 417-422. doi: 10.1007/s10529005-1776-Z

Aguedo, M., Wache, Y., Coste, F., Husson, F., \& Belin, J. M. (2004). Impact of surfactants on the biotransformation of methyl ricinoleate into gammadecalactone by Yarrowia lipolytica. Journal of Molecular Catalysis B-Enzymatic, 29(1-6), 31-36. doi: 10.1016/j.molcatb.2003.11.018

Alchihab, M., Destain, J., Aguedo, M., Majad, L., Ghalfi, H., Wathelet, J. P., \& Thonart, P. (2009). Production of gamma-decalactone by a psychrophilic and a mesophilic strain of the yeast Rhodotorula aurantiaca. Applied Biochemistry and Biotechnology, 158(1), 41-50. doi: 10.1007/s12010-008-8297-x

An, J.-U., Joo, Y.-C., \& Oh, D.-K. (2013). New biotransformation process for production of the fragrant compound $\gamma$-dodecalactone from 10-hydroxystearate by permeabilized Waltomyces lipofer cells. Applied and Environmental Microbiology, 79(8), 2636-2641. doi: 10.1128/AEM.02602-12

Barth, G., \& Gaillardin, C. (1996). Yarrowia lipolytica Nonconventional Yeasts in Biotechnology: A Handbook (pp. 313-388). Berlin, Heidelberg: Springer Berlin Heidelberg.

Baser, K. H. C., \& Demirci, F. (2007). Chemistry of essential oils. In R. G. Berger (Ed.), Flavours and fragrances: chemistry, bioprocessing and sustainability (pp. 43-86). Berlin: Springer.

Braga, A., \& Belo, I. (2013). Immobilization of Yarrowia lipolytica for aroma production from castor oil. Applied Biochemistry and Biotechnology, 169(7), 2202-2211. doi: 10.1007/s12010-013-0131-4

Braga, A., \& Belo, I. (2015). Production of $\gamma$-decalactone by Yarrowia lipolytica: insights into experimental conditions and operating mode optimization. Journal of Chemical Technology \& Biotechnology, 90(3), 559-565. doi $10.1002 /$ jctb. 4349

Darvishi Harzevili, F. (2014). Yarrowia lipolytica in Biotechnological Applications Biotechnological Applications of the Yeast Yarrowia lipolytica (pp. 17-74). Cham: Springer International Publishing.

Dufosse, L., Feron, G., Mauvais, G., Bonnairme, P., Durand, A., \& Spinnler, H. E. (1998). Production of gamma-decalactone and 4-hydroxy-decanoic acid in the genus Sporidiobolus. Journal of Fermentation and Bioengineering, 86(2), 169173

Feron, G., Blin-Perrin, C., Krasniewski, I., Mauvais, G., \& Lherminier, J. (2005). Metabolism of fatty acid in yeast: Characterisation of beta-oxidation and ultrastructural changes in the genus Sporidiobolus sp cultivated on ricinoleic acid methyl ester. FEMS Microbiology Letters, 250(1), 63-69. doi 10.1016/j.femsle.2005.06.045

Fraley, S., Oom, M., Terrien, B., \& Alewsk, J. (2007). Design of Experiments via Taguchi Methods: Orthogonal Arrays. USA: The Michigan Chemical Process Dynamic and Controls Open Text Book.

Gomes, N., Braga, A., Teixeira, J. A., \& Belo, I. (2013). Impact of lipasemediated hydrolysis of castor oil on $\gamma$-decalactone production by Yarrowia lipolytica. Journal of the American Oil Chemists' Society, 90(8), 1131-1137. doi 10.1007/s11746-013-2231-2

Gomes, N., Teixeira, J. A., \& Belo, I. (2010). The use of methyl ricinoleate in lactone production by Yarrowia lipolytica: Aspects of bioprocess operation that 
influence the overall performance. Biocatalysis and Biotransformation, 28, 227 234.

Groguenin, A., Wache, Y., Garcia, E. E., Aguedo, M., Husson, F., LeDall, M. T., ... Belin, J. M. (2004). Genetic engineering of the beta-oxidation pathway in the yeast Yarrowia lipolytica to increase the production of aroma compounds. Journal of Molecular Catalysis B-Enzymatic, 28(2-3), 75-79. doi: 10.1016/j.molcatb.2004.01.006

Lee, S. L., \& Chou, C. C. (1994). Growth and production of gamma-decalactone and Cis-6-dodecen-4-olide by Sporobolomyces odorus in the presence of fatty acids and oils. Journal of Fermentation and Bioengineering, 78(1), 114-116.

Lee, S. L., Lin, S. J., \& Chou, C. C. (1995). Growth of and production of $\gamma-$ decalactone by Sporobolomyces odorus in jar fermentors as affected by $\mathrm{pH}$, aeration and fed-batch technique. Journal of Fermentation and Bioengineering, 80(2), 195-199.

Longo, M. A., \& Sanromán, M. A. (2006). Production of food aroma compounds: microbial and enzymatic methodologies. Food Technology and Biotechnology, 44, 335-353.

Maume, K. A., \& Cheetham, P. S. J. (1991). The production of $\gamma$-decalactone by fermentation of castor oil. Biocatalysis and Biotransformation, 5(2), 79-97. doi: doi:10.3109/10242429109014857

Montgomery, D. C. (1991). Design and Analysis of Experiments. New York: John Wiley \& Sons.

Moradi, H., Asadollahi, M. A., \& Nahvi, I. (2013). Improved $\gamma$-decalactone production from castor oil by fed-batch cultivation of Yarrowia lipolytica. Biocatalysis and Agricultural Biotechnology, 2(1), 64-68. doi http://dx.doi.org/10.1016/j.bcab.2012.11.001

Neto, R. S., Pastore, G. M., \& Macedo, G. A. (2004). Biocatalysis and biotransformation producing gamma-decalactone. Journal of Food Science, 69(9), C677-C680.

Okui, S., Uchiyama, M., \& Mizugaki, M. (1963). Metabolism of hydroxyl fatty acids. II. Intermediates of the oxidative breakdown of ricinoleic acid by genus Candida. Journal of Biochemistry, 54, 536-540.

Patil, A. A., Sachin, B. S., Wakte, P. S., \& Shinde, D. B. (2014). Optimization of supercritical fluid extraction and HPLC identification of wedelolactone from Wedelia calendulacea by orthogonal array design. Journal of Advanced Research, 5(6), 629-635. doi: 10.1016/j.jare.2013.09.002

Puthli, M. S., Rathod, V. K., \& Pandit, A. B. (2006). Enzymatic hydrolysis of castor oil: Process intensification studies. Biochemical Engineering Journal, 31(1), 31-41. doi: http://dx.doi.org/10.1016/j.bej.2006.05.017

Romero-Guido, C., Belo, I., Ta, T., Cao-Hoang, L., Alchihab, M., Gomes, N., . . Waché, Y. (2011). Biochemistry of lactone formation in yeast and fungi and its utilisation for the production of flavour and fragrance compounds. Applied Microbiology and Biotechnology, 89(3), 535-547. doi: 10.1007/s00253-0102945-0

Scharder, J. (2007). Microbial flavour production. In R. G. Berger (Ed.), Flavours and fragrances: chemistry, bioprocessing and sustainability (pp. 507574). Berlin Springer.

Schrader, J., Etschmann, M. M. W., Sell, D., Hilmer, J. M., \& Rabenhorst, J. (2004). Applied biocatalysis for the synthesis of natural flavour compounds current industrial processes and future prospects. Biotechnology Letters, 26(6), 463-472. doi: 10.1023/B:BILE.0000019576.80594.0e

Waché, Y. (2013). Production of Dicarboxylic Acids and Flagrances by Yarrowia lipolytica. In G. Barth (Ed.), Yarrowia lipolytica: Biotechnological Applications (pp. 151-170). Berlin, Heidelberg: Springer Berlin Heidelberg.

Wache, Y., Aguedo, M., LeDall, M. T., Nicaud, J. M., \& Belin, J. M. (2002). Optimization of Yarrowia lipolytica's beta-oxidation pathway for gammadecalactone production. Journal of Molecular Catalysis B-Enzymatic, 19, $347-$ 351.

Wache, Y., Aguedo, M., Nicaud, J. M., \& Belin, J. M. (2003). Catabolism of hydroxyacids and biotechnological production of lactones by Yarrowia lipolytica. Applied Microbiology and Biotechnology, 61(5-6), 393-404. doi: 10.1007/s00253-003-1207-1 